\title{
Factors Affecting Knowledge and Utilization of Contraceptive Methods Among Women Visiting Gynecological Out Patient Department: A Single Centre Study
}

\author{
${ }^{1}$ Ameelia Sadaqat, ${ }^{2}$ Hijab Batool, ${ }^{1}$ Yasmin Rashid, ${ }^{1}$ Rana Abid, ${ }^{1}$ Naila Abbas, ${ }^{1}$ Shafaq Naz \\ ${ }^{I}$ Department of Obstetrics \& Gynecology, Central Park Teaching Hospital, Lahore \\ ${ }^{2}$ Department of Chemical Pathology, Central Park Medical College, Lahore
}

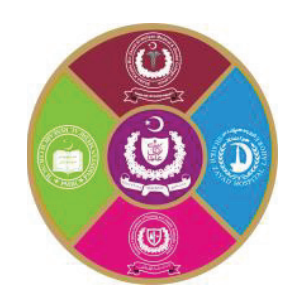

\begin{abstract}
Introduction: Due to limited resources and compromised health care facilities, developing countries have an unmet need for contraception among general population. Unplanned pregnancies are reported to end in unsafe abortions and increased maternal morbidity and mortality. Poor knowledge and awareness about contraception among general population and health professionals can be a major contributing factor towards malpractice of contraception. Aims \& Objectives: This study was conducted to find out different factors which play role in contraceptive utilization and knowledge among women. Place and duration of study: This study was conducted in the department of Gynecology and Obstetrics, Central Park Medical College Lahore, from July 2017 to December 2017. Material \& Methods: Our study design was cross sectional analytical. Married women in reproductive age attending gynecological outdoor of Central park teaching hospital were asked to fill a pre designed questionnaire. This questionnaire included questions regarding personal and past medical details of participants, knowledge about contraception, frequency of utilization of different contraceptive methods and reasons for using or not using contraceptive methods. Results: In our survey, majority of participants $(66.7 \%)$ had good knowledge about contraception. Out of all those having knowledge, only $13.4 \%$ were using contraception at the time of survey. The major factors which were seen in the group using contraception were education, husband cooperation, husband occupation and power of decision making. Women who were not using any protection against pregnancy despite having good knowledge told that main reasons for not using contraception was fear of side effects, urge to complete family, religious reasons and non-cooperative spouse. Conclusion: To decrease the rate of unplanned pregnancies and decrease maternal mortality and morbidity it is important to study above factors in detail. Increasing the level of education among women and awareness sessions in general population can improve contraception utilization.
\end{abstract}

Key words: contraception, knowledge, factors.

\section{INTRODUCTION}

W orld health organization (WHO) defines contraception as use of any method that interferes with the process of reproduction. Contraceptive use helps couples and individuals realize their basic right to decide freely and responsibly if, when and how many children to have. There is a high unmet need for contraception among women of developing countries. Many young females are reporting unplanned pregnancies at an alarming rate in these developing regions. ${ }^{1}$ Most of the times, these unplanned pregnancies are associated with unsafe abortions outside the hospital settings resulting in increased risk of maternal morbidity and mortality. ${ }^{2}$ Therefore, to prevent all these unwanted outcomes of unplanned pregnancies, there is a need for introducing an interventional program to improve the knowledge and utilization of contraceptive methods among women of developing countries.

United Nations published a report on trends in contraceptive use worldwide in 2015 and found that contraceptive use has been increased in many parts of the world including Asia. ${ }^{3}$ This situation seems to be a little bit different in Pakistan. The government of Pakistan has calculated the overall contraceptive performance of 2015-16 in terms of couple years of 
protection (CYP) and compared this with the year 2014-15. This comparison showed that the overall contraceptive performance in 2015-16 was decreased by $10.4 \%$ in comparison with the performance of the last year. Worst performance was seen in the province of Sindh followed by Khyber Pakhtunkhwah. ${ }^{4}$ Many factors can explain the above stated decrease in the use of contraception like lack of knowledge regarding practice of contraceptive methods among Pakistani women or inaccessibility to contraceptive methods or medical help. Proper practice of contraception is crucial for societies as well as health care practitioners to reduce unwanted gynecological complications, maternal morbidity and mortality. Lack of proper knowledge and awareness about contraception among general population and healthcare workers can be a major contributing factor towards malpractice of contraception. ${ }^{5}$

We designed this study to assess knowledge, attitude and trends of practice of different contraceptive methods among women visiting gynecological outpatient department of Central Park Medical College Lahore. This study was also aimed at identification of different factors which can influence the use of contraceptives among general population.

\section{MATERIAL AND METHODS}

This was a cross sectional study conducted in the department of Gynecology and Obstetrics, Central Park Medical College Lahore. A questionnaire was designed which included questions regarding personal information of the participants, child bearing intentions in the future and knowledge and practice of different contraceptive methods. The questionnaire also included some questions like accessibility to family planning centers and cooperation of spouse to identify different factors which can play role in practice of contraception to avoid unplanned pregnancies. A total of 125 women who visited the Gynecology and obstetrics department were asked to fill the questionnaire. Consent was taken from all participants and the aim of study was explained to them before asking them questions. All of the participating women were told that the information will remain confidential and their identity will never be disclosed at any time of the study. Women with gynecological and obstetrical emergencies, unmarried females and women in their menopause were excluded from the study. Married females in the reproductive age ( $<50$ years $)$ without any medical emergencies were included in the study. This study was conducted from July 2017 to December 2017.

\section{Statistical analysis:}

The data was collected and analysis was performed on SPSS 23.0. Ethical approval was obtained from Ethical Review Committee of Central Park Medical College.

\section{RESULTS}

A total of 125 women participated in our survey. Out of the above, $66.7 \%$ had some knowledge about contraception, while $33.3 \%$ had absolutely no knowledge.

\begin{tabular}{|c|c|}
\hline Statement & \begin{tabular}{|c|} 
Percentage of \\
participants responding \\
to the statement
\end{tabular} \\
\hline $\begin{array}{l}\text { Knowledge about specific } \\
\text { contraceptive methods } \\
\text { I know about pills } \\
\text { I know about condoms } \\
\text { I know about intrauterine } \\
\text { contraceptive devices } \\
\text { I have no knowledge about } \\
\text { any method }\end{array}$ & $\begin{array}{l}60.7 \% \\
21.5 \% \\
12.4 \% \\
5.4 \%\end{array}$ \\
\hline $\begin{array}{l}\text { What type of media exposure } \\
\text { helped you to get knowledge } \\
\text { about contraception } \\
\text { News paper } \\
\text { TV/radio } \\
\text { Internet } \\
\text { I do not get any help from } \\
\text { media exposure }\end{array}$ & $\begin{array}{l}17.9 \% \\
63.4 \% \\
2.7 \% \\
16.0 \%\end{array}$ \\
\hline
\end{tabular}

Table-1: Knowledge and source of different methods

Women who had knowledge, mostly were aware of contraceptive pills $(60.7 \%)$, condoms $(21.5 \%)$ and only $12.4 \%$ women knew about intrauterine contraceptive device. Regarding awareness, TV/Radio played a major role $(63.4 \%)$ in creating awareness among women who had knowledge about contraception. $17.9 \%$ of women came to know about contraception through print media and a very small number $(2.7 \%)$ of women gained knowledge through internet/social media. (Table-1)

Contraception users: Out of the $66.7 \%$ women who had knowledge of contraceptive methods $13.4 \%$ were using some form of birth control at the time of this survey. Fig-1 shows the percentage of different methods being used. 


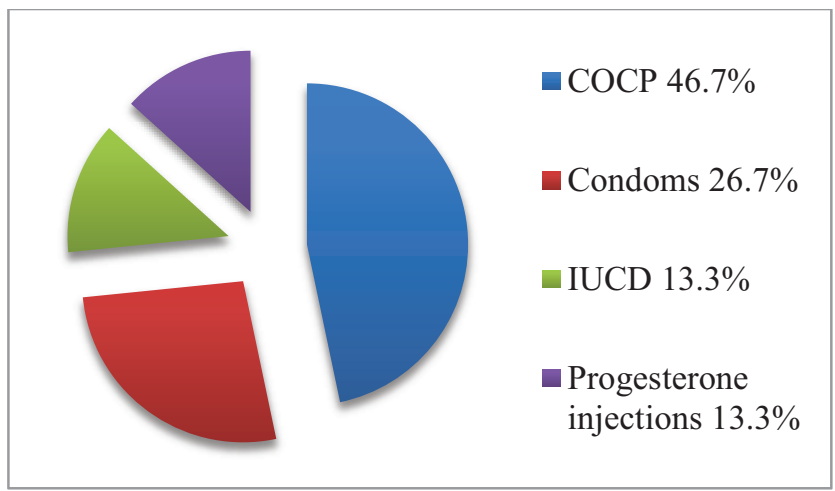

Fig-1: Percentage of participants using different contraceptive methods.

Private clinics were the major source $(47.3 \%)$ of provision of contraceptive methods followed by lady health workers $(33.9 \%)$ and government operated green star clinics (18.8\%).

$91 \%$ of women in the contraceptive users group were educated (Fig-2) and similar trend was observed in relation to education of their husbands (93.2\%) (Fig-3).



Fig-2: Level of woman's education among contraceptive users

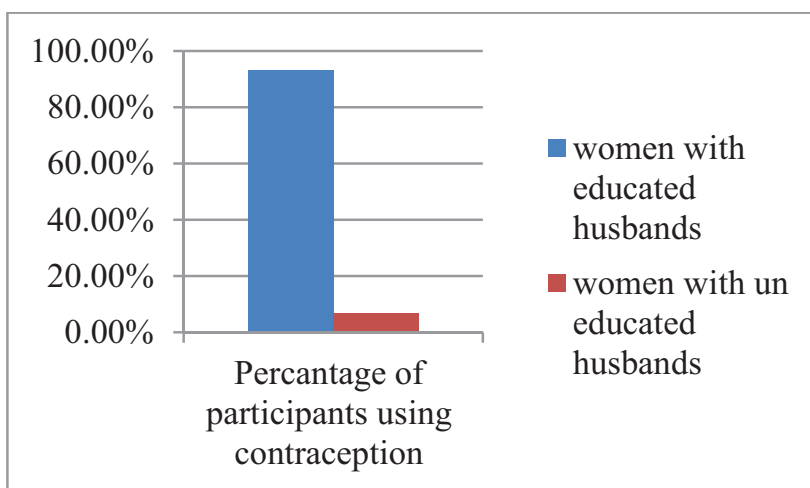

Fig-3: Husbands' education and contraception usage.

Contraception usage was best (73\%) among the wives of salaried persons as compared to women with husbands in other occupations. $68.8 \%$ of women using contraception stated that they had their husband's cooperation regarding use of contraception. $72.3 \%$ of women using contraception thought that they were given the opportunity to involve in decision making of other life aspects as well .

Non-users of contraception: $86.6 \%$ of our survey participants were non-users of contraception. $47.3 \%$ had access to contraceptive services but still did not use contraception. $40.2 \%$ of women thought most contraceptive techniques have a lot of side effects while another major deterrent was non-cooperative spouse. Only $11.3 \%$ women thought that contraception is forbidden in Islam. $24.8 \%$ women still wanted to reproduce more children considering their family to be incomplete. (Fig-4)

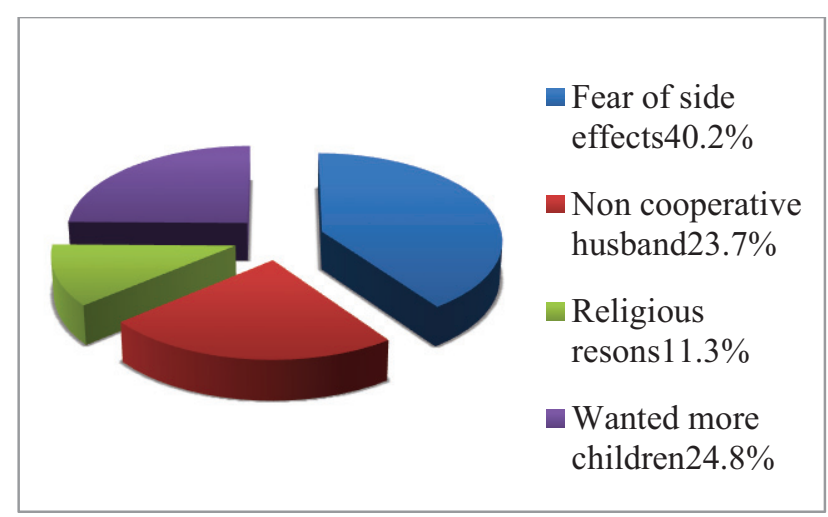

Fig-4: Reasons of non-usage of contraception

More than half of the women (52.7\%) told that they had altogether no access to medical care and this is the reason they are not using any contraception.

\section{DISCUSSION}

Several factors play important role in determining reproductive health of population and improving access to reproductive health facilities is an important step to improve community health. ${ }^{6}$ In our study it was found that women between 30 to 40 years of age use contraception more frequently as compared to other age groups. This may be due to the fact that with advancing age there is advanced maturity and knowledge. Low utilization of contraception in younger age group might be due to the fact that newly married couples tend to complete their family first before switching to any method of contraception.

Contraception with the help of pills was most popular among the participants followed by barrier method of contraception. Overall, short-term and reversible methods, such as the pill, injectable and male condom, are more common than other methods in Africa and Europe whereas long-acting or permanent methods, such as sterilization, implants 
and the IUD, are more common in Asia and Northern American.

In this study we found certain factors, which affected contraception use among participants. These factors were education of women, education of male partner, occupation of husband, fear of side effects and availability of different contraceptive methods.

In any society, good reproductive health depends upon how well community is informed upon contraception issues. Education appeared to be an important factor in our study as well-educated participants and wives of well-educated husbands were found to have better knowledge and utilization of contraception. A similar study was conducted in Nepal which found that educated women with highly educated male partners were among the most frequent users of contraception and use of contraception was also highest in women with higher education. ${ }^{7}$ In another study it was observed that contraception utilization increased with increasing literacy level of women. ${ }^{8}$ Education seems to put a direct influence upon utilization of contraception. In this region Sri Lanka has the highest contraceptive prevalence rate of $68.4 \%$ with a literacy rate as high as $98 \%$. According to recent statistics, the literacy rate of Bangladesh and India is more than $70 \%$ (year 2017) whereas the literacy rate of Pakistan has declined from 60 percent to $58 \%$ in 2016-17.

Most of the participants who did not use contraception in our study avoided it because of the fear of side effects followed by non-cooperation by the spouse in this matter. In a Pakistani survey conducted in Sindh, the main reasons given by females for not using contraceptives were also fear of side effects, intention of having more children and religious restrictions. ${ }^{9}$ Similar findings were observed in another study in which respondents who had no side effects were using contraception more as compared to those who had experienced some sort of side effects. ${ }^{10}$ In another study the most common reasons given by women on not using contraception was plan to have more children, divorced or broken family and fear of side effects. ${ }^{11}$ The participants in our study also stated religious constraint as one of the reason for not using contraceptives. These results are contrary to the popular belief that religion Islam is against the use of contraception. A study conducted in West Bengal revealed that percentage of women having knowledge of contraception methods is higher among non-Muslim as compared to Muslim women. There was also a higher rate of illiteracy among
Muslim women which aggravated their condition of not using the contraception. ${ }^{12}$

Communication between partners and involvement in decision making is a very important factor in contraception utilization when required. In our study, women who were involved in decision making used contraception more as compared to the participants who were not involved in any sort of decision making. Similar results were observed in a study conducted among migrant women in which, those involved in decision making were among the best users of contraception. ${ }^{13}$

A study conducted in Ghana found some socioeconomic factors that played some role in acceptance and utilization of family planning methods. These factors were education, accessibility to contraceptive methods, knowledge about contraception, family preference and employment. Among all the factors, knowledge about methods of contraception and how to gain access to these methods was the most important variable. ${ }^{14}$

Non-availability is one of the major issues in non usage of contraception. According to a survey conducted in 2012/2013 there was 20.1\% unmet need of contraception by married women in Pakistan. ${ }^{15}$ In our survey which was conducted in a suburban population it was found to be $52.7 \%$.

Pakistan is one of developing countries with an alarming population growth rate. In Pakistan condoms are more commonly used than any other form of contraception. This barrier method is followed closely by female sterilization. ${ }^{16}$

\section{CONCLUSION}

Pakistan is facing rapid population growth and this increasing rate is a challenge for government as well as health care providers. Increase in contraceptive prevalence is in furtherance of women education, women empowerment, access to medical help, reduction in maternal and infant mortality and upswing in economic outcomes. These factors should be studied and emphasized further to improve general community health and avoiding unplanned pregnancies.

\section{REFERENCES}

1. Akintade OL, Pengpid S, Peltzer K. Awareness and use of and barriers to family planning services among female university students in Lesotho. South African Journal of Obstetrics and Gynaecology. 2011; 17(2):36-42. 
2. World Health Organisation: Making Pregnancy Safer: Annual Report 2007. In.: World Health Organization, Geneva; 2008.

3. United Nations, Department of Economic and Social Affairs, Population Division (2015). Trends in Contraceptive Use Worldwide 2015 (ST/ESA/SER.A/349).

4. Government of Pakistan Statistics Division Pakistan Bureau of Statistics. Contraceptive Performance Report 2015-2016. 2017.

5. Elkalmi RM, Khan MU, Ahmad A, Srikanth AB, Abdurhaman NS, Jamshed SQ, Awad AI, Ab Hadi HB. Knowledge, awareness, and perception of contraception among senior pharmacy students in Malaysia: A pilot study. J Res Pharm Pract 2015; 4:94-8

6. New J, Cahill N, Stover J, Gupta Y, Alkema L. Levels and trends in contraceptive prevalence, unmet need, and demand for family planning for 29 states and union territories in India: a modelling study using the Family Planning Estimation Tool. The Lancet Global Health. 2017; 5(3):350-358.

7. Gubhaju B. The Influence of Wives' and Husbands' Education Levels On Contraceptive Method Choice in Nepal, 1996-2006. International Perspectives on Sexual and Reproductive Health. 2009; 35(04):176-185.

8. Tehrani FR, Farahani FKA, Hashemi MS. Factors influencing contraceptive use in Tehran. Family Practice 2001; 18: 204-208.

9. Bibi S, Memon A, Memon Z, Bibi M. Contraceptive knowledge and practices in two districts of Sindh, Pakistan: A hospital based study. J Pak Med Assoc. 2008; 58(5):254-57.

10. Bhandari N, Shrestha G, Thakuri P. Study of factors affecting contraceptive use among married women of reproductive Age. Journal of College of Medical Sciences-Nepal. 2014; 9(4).

11. Debebe S, Andualem Limenih M, Biadgo B. Modern contraceptive methods utilization and associated factors among reproductive aged women in rural Dembia District, northwest Ethiopia: Community based cross-sectional study. International Journal of Reproductive BioMedicine. 2017; 15(6):367-374.

12. Hussain N. Demographic, Socio-Economic and Cultural Factors Affecting Knowledge and Use of Contraception Differentials in Malda District, West Bengal. Journal of Community Medicine \& Health Education. 2011; 01(01).

13. Thwin T, Kamsrichan W, Chompikul J. Factors related to the contraceptive use among married migrant women of reproductive age in Maesot, Tak province, Thailand. Journal of Public Health and Development. 2006; 6(1):134-143.

14. Adjei D, Owusu SJ, Asiedu M, Acheampong SI. Psychosocial factors affecting contraceptive usage: a case of unmet needs in Ghana. European Scientific Journal. 2014; 10(15):84-8.

15. Sedgh G, Hussain R. Reasons for Contraceptive Nonuse among Women Having Unmet Need for Contraception in Developing Countries. Studies in Family Planning. 2014; 45(2):151-169.

16. Howse K, Nanitashvil N. Contraceptive methods used by younger women: South Asia. UK: Population Horizons; 2014.

\section{The Authors:}

Dr. Ameelia Sadaqat

Assistant Prof,

Department of Obstetrics and Gynaecology,

Central Park Teaching Hospital, Lahore.

Dr. Hijab Batool

Assistant Prof,

Department of Chemical Pathology,

Central Park Teaching Hospital, Lahore.

Prof. Yasmin Rashid

Department of Obstetrics and Gynaecology, Central Park Teaching Hospital, Lahore.

Rana Abid

Post Graduate Trainee,

Department of Obstetrics and Gynaecology,

Central Park Teaching Hospital, Lahore.

Naila Abbas

Post Graduate Trainee,

Department of Obstetrics and Gynaecology,

Central Park Teaching Hospital, Lahore.

Shafaq Naz

Post graduate Trainee,

Department of Obstetrics and Gynaecology,

Central Park Teaching Hospital, Lahore.

\section{Corresponding Author:}

Dr. Hijab Batool

Assistant Prof,

Department of Chemical Pathology,

Central Park Teaching Hospital, Lahore.

E-mail: batool.hijab@gmail.com 